\title{
GASTOS SOCIAIS E ACCOUNTING GIMMICKS: UMA PERCEPÇÃO DOS CICLOS POLÍTICOS ELEITORAIS NOS MUNICÍPIOS DO CENTRO- OESTE BRASILEIRO
}

Nilton Oliveira da Silva 1

Fátima de Souza Freire 2

- Artigo recebido em: 24/01/2020 -- Artigo aceito em: 11/06/2020 -.- Segunda versão aceita em: 05/07/2020

\section{RESUMO}

Essa pesquisa objetivou verificar em que extensão as práticas de accounting gimmicks afetam as políticas fiscais e a execução dos gastos sociais durante os ciclos políticos eleitorais. Por meio de um modelo logit, foram analisadas as contas públicas dos 466 municípios da região centro-oeste brasileira em um painel desbalanceado no período de 2004 a 2017. Com uma especificidade singular, os municípios brasileiros têm apresentado dificuldades na manutenção de um desempenho fiscal eficiente. Uma abordagem teórica dos regimes fiscais enfatiza que a rigidez fiscal pela qual os governantes são conduzidos pode impulsionar práticas de manipulações contábeis, especialmente nos saldos do SFA (Stockflow adjustment). Tais práticas visam melhorar os resultados orçamentários, a visibilidade política e a permanência no poder. Os achados permitiram corroborar parcialmente com a literatura de que há uma relação positiva entre as regras fiscais rígidas e as práticas de accounting gimmicks. Ainda foi possível constatar que situações de elevados índices de dependência financeira e de oportunismo político para reeleição são impulsionadores nas ocorrências dessas manipulações. Portanto, concluiu-se que a utilização dos gastos sociais, alinhados a uma abordagem teórica dos regimes fiscais rígidos e da Teoria dos Ciclos Políticos Eleitorais, é influenciada pelo comportamento oportunista dos gestores e pelas práticas de accounting gimmicks.

Palavras-chave: Accounting gimmicks. Stock-flow adjustment. Regras fiscais. Gastos Sociais. Ciclos políticos eleitorais.

\footnotetext{
'Doutorando em Ciências Contábeis pelo Programa de Pós-graduação em Ciências Contábeis da Universidade de Brasília. Servidor Público do Governo do Distrito Federal. Endereço: Bloco B2, $1^{\circ}$ andar, sala B1-54/4, FACE- UnB, Brasília/DF, Brasil, CEP.: 70910-900. Tel. +55 (61) 31070897. E-mail: niltonos2@gmail.com.

https://orcid.org/0000-0003-3500-1903
}

2 Doutora em Economia pela Université de Sciences Sociales de Toulouse I, France. Professora titular do Programa de Pós-graduação em Ciências Contábeis e do Departamento de Ciências Contábeis e Atuariais da Universidade de Brasília. Endereço: Bloco B2, $1^{\circ}$ andar, sala B1-54/4, FACE- UnB, Brasília/DF, Brasil, CEP.: 70910-900. Tel. +55 (61) 31070897. E-mail: ffreire@unb.br.

http://orcid.org/0000-0003-1133-5087

Editor responsável pela aprovação do artigo: Dr. João Estevão Barbosa Neto

Editora responsável pela edição do artigo: $\mathrm{Dr}^{\mathrm{a}}$. Bruna Camargos Avelino 


\title{
SOCIAL SPENDING AND ACCOUNTING GIMMICKS: A PERCEPTION OF ELECTORAL POLITICAL CYCLES IN BRAZIL'S MIDWEST
}

\begin{abstract}
This research aimed to verify to what extent the practices of accounting gimmicks affect fiscal policies and the execution of social spending during political electoral cycles. We use a logit model to analyze the public accounts of 466 municipalities in Brazil's Midwest region in an unbalanced panel from 2004 to 2017 . With a unique specificity, Brazilian municipalities have shown difficulties in maintaining efficient fiscal performance. A theoretical approach to fiscal regimes emphasizes that the fiscal rigidity by which governments are led can boost accounting manipulation practices, especially in SFA (Stock-flow adjustment). Such practices aim to improve budget results to increase political visibility and stay in power. The findings allowed to partially corroborate with the literature that there is a positive relationship between the rigid fiscal rules and the practices of accounting gimmicks. It was also possible to verify that situations of high levels of financial dependence and political opportunism for reelection are drivers in the occurrences of these manipulations. Therefore, it was concluded that the use of social spending, in line with a theoretical approach to rigid tax regimes and the Theory of Political Electoral Cycles, is influenced by the opportunistic behavior of managers and by the practices of accounting gimmicks.
\end{abstract}

Keywords: Accounting gimmicks. Stock-flow adjustment. Fiscal Rules. Social public spending. Electoral political cycles.

\section{INTRODUÇÃO}

A complexidade da gestão pública tem gerado grandes esforços na conciliação eficiente da execução dos gastos, prestação de serviços e o cumprimento das metas fiscais. A criação da Lei de Responsabilidade Fiscal (LRF) em 2000, trouxe uma nova visão para a política fiscal brasileira. Nessa nova dimensão está a frenagem da elevação descontrolada dos gastos públicos em decorrência do aumento das demandas sociais do governo com políticas distributivas e com objetivo de controle político, além de uma maior responsabilização do gestor quanto à utilização desses gastos (Santos, Machado \& Scarpin, 2013).

Em primeiro lugar, a relação gasto público e arrecadação é a meta a ser alcançada pelos diversos governos para manter a economia equilibrada, pois, os custos de uma indisciplina fiscal podem afetar diretamente a estabilização da economia (Montes \& Alves, 2012). No entanto, a probabilidade de um insucesso no equilíbrio fiscal aumenta à medida que a demanda por serviços públicos exceda massivamente a alocação de recursos. Para controlar os efeitos negativos dessa situação e tentar solucionar os problemas, os governos adotam modelos de regras fiscais (Vinnari \& Näsir, 2008).

A literatura empírica e teórica tem apresentado, por meio de uma abordagem política-institucional, uma forma de explicar o fenômeno do comportamento econômico e a intervenção do Estado. Dessa maneira, os regimes fiscais agem como agentes estratégicos de direcionamento da 
orientação política governamental. Estão classificados em três tipos distintos: ideal, flexível e rígido (Von Hagen \& Wolff, 2006; Menezes \& Tonedo Junior, 2006; Gobetti, 2014; Lledó, Yoon, Fang, Mbaye \& Kim, 2017; Gonçalves, 2018).

Enquanto uma corrente de pesquisadores apresenta as regras fiscais restritivas como sendo eficazes e capazes de reduzir o déficit, inflação e taxa de juros, além de se adaptarem mais rapidamente às recessões inesperadas (Besley \& Case, 2003; Fatás \& Mihov, 2006; Arestis \& Sawyer, 2008; Sacchi \& Salotti, 2015), outra corrente sinaliza que as regras podem induzir as distorções dos gastos públicos contra os investimentos, bem como o aumento da carga tributária (Milesi-Ferreti, 2003; Von Hagen \& Wolff, 2006; Gobetti, 2014; Oskaya, 2014). Neste último caso, o gestor público tenderá a reduzir o grau de transparência fiscal, além de provocar despesas artificiais ou receitas não recorrentes com o intuito de cumprir as metas estabelecidas.

Além do mais, com a imposição de metas fiscais, os governantes reduzem seu poder discricionário do uso do gasto público impossibilitando que os recursos sejam aplicados em atividades de preferências alocativas oportunistas (Salvador, 2016). Nesse contexto de regimes fiscais rígidos, mais especificamente voltados a regras numéricas, a accounting gimmicks ou truques contábeis, parece ser mais recorrente (Buti, Martins, \& Turrini, 2007). O conceito de accounting gimmicks está ligado ao contexto fiscal, no qual os governos utilizam de uma variedade de tentativas (truques) deliberadas com o objetivo de uma melhora na aparência de suas contas públicas (Alt, Lassen, \& Wehner, 2014).

Conforme Gobetti (2014), o regime fiscal brasileiro é considerado como rígido e precisa passar por uma restruturação para se distanciar de um viés deficitário com natureza política. Não obstante, a falta de regulamentação criteriosa e escolhas racionais dos governantes tem permitido que os gastos públicos sofram com o desencontro entre dispêndio e investimentos, comprometendo a qualidade do serviço prestado. Nesse contexto, o gestor público, que muitas vezes não consegue realizar as promessas eleitorais, procura artifícios contábeis para ajustar os resultados fiscais e cumprir as metas estabelecidas nos planos de governo (Dalmonech, Sant'Anna, Coimbra, \& Teixeira, 2008).

Nessa perspectiva, os políticos possuem incentivos para desvirtuar a política fiscal local em períodos pré-eleitorais, de modo a aumentarem sua probabilidade de permanência ou sucessão de aliados no poder. O objetivo desse estudo é verificar a influência das práticas de accounting gimmicks nos gastos sociais em períodos dos ciclos políticos eleitorais nos municípios do Centro-Oeste. Para isso, foram analisadas as informações das contas regionais e das finanças públicas dos municípios. Os dados estão apresentados em um painel desbalanceado, no período de 2004 a 2017, compreendendo quatro ciclos eleitorais - 2004, 2008, 2012 e 2016.

Sabe-se que há disparidades do contexto político e econômico interregional (Simonassi \& Cândido Junior, 2008). Outro ponto importante está no fato de que as regiões com baixo poder aquisitivo e governos subnacionais tendem a sofrer maior influência do comportamento oportunista de políticos alinhados à prática clientelista que manipulam os gastos públicos. A este respeito, justifica-se o estudo já que a existência de regras fiscais mais restritas pode induzir a manipulação de dados por parte do governo, haja vista que os truques são meios 
Gastos Sociais e Accounting Gimmicks: Uma Percepção dos Ciclos Políticos Eleitorais nos Municípios do Centro-Oeste Brasileiro

suficientes para ludibriar os envolvidos com o intuito de conseguir o cumprimento das metas.

\section{REVISÃO DE LITERATURA}

\subsection{Accounting Gimmicks}

A literatura tem se empenhado em apresentar um longo e extenso conhecimento a respeito das manipulações contábeis no contexto corporativo. Entretanto, para as atividades ocorridas no cenário governamental, o esforço acadêmico não recebeu tamanha importância (Beck, 2018). Isso se contrapõe a nova perspectiva social voltada a processos mais transparentes e com maiores níveis de responsabilização dos gestores.

Eventualmente, na publicação dos resultados governamentais pode ocorrer uma tendência à divulgação de informações positivas e que satisfaçam aos usuários do serviço público. A partir disso, surge uma atração à prática de artifícios contábeis, ou melhor, accounting gimmicks. Esse termo tem similar relação conceitual com a expressão contabilidade criativa. Sua origem remonta aos comentários realizados pelos profissionais da área contábil e pela mídia sobre as atividades ocorridas no setor público na tentativa de demonstrar aos usuários uma realidade diferente, principalmente no contexto econômico. Assim, ambos os termos são considerados de extrema generalidade e distanciados de qualquer teoria específica (Stolowy \& Breton, 2004; Beck, 2018).

A intenção está em manobrar a realidade, principalmente orçamentária, a fim de que as contas públicas apresentem um desempenho positivo e que as transações governamentais assumam uma melhora no saldo orçamental. Conforme Alt et al. (2014), a prática de accounting gimmicks está relacionada às escolhas que os governantes realizam na relação com os seus eleitores. Uma dessas escolhas diz respeito aos ajustes de impostos e de despesas, mesmo observando as regras fiscais impostas. Esse fato minimiza pressões institucionais, porém, pode gerar uma impopularidade. É importante que se exclua disso os fatores não-cíclicos, como catástrofes naturais, que proporcionam grandes gastos não previstos (Koen \& Van den Noord, 2005).

Oskaya (2014) identificou que a accounting gimmicks pode ultrapassar as estruturas internas de um governo. Com base em dados da dívida pública da Turquia, os resultados de suas pesquisas identificaram que o governo praticava artifícios contábeis para transmitir informações distorcidas ao Fundo Monetário Internacional (FMI) e amenizar pressões internacionais. No Brasil, Gobetti e Orair (2017) apresentaram que a accounting gimmicks se tornou uma prática comumente utilizada na tentativa de minimizar ou evitar a rigidez do regime fiscal de metas de resultado primário, prejudicando a informação confiável da série histórica para uma análise da política fiscal.

Nessa perspectiva, os estudos empíricos e teóricos que buscam mensurar os níveis de gerenciamento de resultados ou de artifícios contábeis no cenário público, diferentemente do cenário privado, ainda são incipientes. Para Goto e Yamamoto (2018), o trabalho apresentado por Milesi-Ferrati (2003) é uma exceção para a insuficiência dos estudos teóricos na área. A autora apresentou um pressuposto teórico que elucida as ações dos governos sobre efeitos das regras fiscais e que podem identificar as práticas de truques contábeis por meio 
dos dados reportados incorretamente. Com isso, são identificadas discrepâncias entre as variações das dívidas e o déficit orçamentário gerando um resíduo estatístico conhecido como Stock-Flow Adjustment - SFA (Alt et al. 2014).

Vale ressaltar que o SFA corresponde a informações contábeis verdadeiras que salientam a dinâmica das dívidas públicas no país e tem como função o monitoramento estatístico de desempenho fiscal. No contexto de uma assimetria informacional do engajamento fiscal, é que este mecanismo pode ser utilizado para expressar inverdades contábeis. Reischmann (2015), utilizou o SFA em seu estudo para examinar as influências de motivações eleitorais na existência de práticas de contabilidade criativa. Foram analisadas as variações do SFA entre os 27 países da OCDE no período de 1970-2011. Para o autor, as tendências de uso de mecanismos para reduzir os déficits se iniciou com a introdução da Stability and Growth Path - SGP (Proposta de Estabilidade e Crescimento) realizada em 1998 pela União Europeia que limitou a relação da dívida/PIB e o déficit para os países membros.

Estudos como Koen e Van den Noord (2005); Von Hagen e Wolff (2006); Weber (2012); Cleménceau e Soguel (2017) também apresentaram por meio desse pressuposto as tendências para uso de accounting gimmicks. No contexto brasileiro, essa abordagem ainda não se encontra amplamente divulgada. No entanto, Gobetti (2010) e Silva (2018) apresentaram informações à literatura nacional. Silva (2018) propôs um modelo adaptado ao trabalho apresentado por Reischmann (2015) e, paralelamente, ponderou o SFA pela Receita corrente liquida $(R C L)$ em virtude dos princípios legais que regem a política fiscal brasileira. A ponderação pretendeu apresentar o grau de envolvimento da variável com o indexador de limites da dívida.

Por outro lado, encontra-se na literatura existente uma gama de variáveis para a explicação do fenômeno das manipulações contábeis nos setores do governo (Rose, 2006; Buti et al., 2007; Oskaya, 2014; Hodges, 2018). Cita-se, por exemplo, na prática brasileira, a variável "restos a pagar". Para Aquino e Azevedo (2017), essa conta orçamentária tem sofrido com a credibilidade na transparência fiscal já que dentro as preferências alocativos do gestor, essas se apresentam como mecanismo de redução de rigidez orçamentária. Corroboram a esse entendimento Alves, Oliveira e Dantas (2007); Costa \& Gardner (2015) e Almeida e Sakurai (2018).

Com efeito, Goto e Yamamoto (2018) afirmam que modelos explicativos podem apresentar resultados insuficientes para a casualidade e detecção dos truques contábeis. No entanto, as variações no SFA, sejam positivas ou negativas, podem permitir análises e inferências da presença de accounting gimmicks. Para a realidade de entes subnacionais, como os municípios brasileiros, o crescente aumento do nível da dívida em situações de rigidez fiscal pode maximizar a opção dos gestores na inserção de truques visando um melhoramento orçamentário (Milesi-Ferrati, 2003). De fato, tais dispersões podem comprometer índices de desempenho socioeconômico e apresentar um gestor com decisões não populares, minimizando sua credibilidade eleitoral e visibilidade política. 
Gastos Sociais e Accounting Gimmicks: Uma Percepção dos Ciclos Políticos Eleitorais nos Municípios do Centro-Oeste Brasileiro

\subsection{Políticas Fiscais e Gastos Públicos}

Há um trade-off entre a teoria e a prática quanto à adoção de regimes fiscais. Teoricamente, as decisões discricionárias de um governante podem alcançar resultados similares aos alcançados pela imposição das regras fiscais ou até mesmo mais eficazes. Entretanto, a realidade prática dos governos se apresenta de outra forma. Dessa maneira, a literatura tem enfatizado que para resolver diversas distorções torna-se necessária a inclusão de regras fiscais (Alesina \& Bayoumi, 1996).

A esse respeito, entende-se que os regimes fiscais são adotados pelos governos como mecanismos estratégicos de direcionamento do comportamento econômico (Gonçalves, 2018). Corroborando a esse entendimento, Menezes e Tonedo Junior (2006) enfatizam que a Teoria das Instituições Orçamentárias fortalece o contexto de uma disciplina fiscal. Segundo Fatás e Mihov (2006), a ideia normativa de regra fiscal está atribuída a um aspecto positivista baseado na realidade de que os governos necessitam de limites e restrições institucionais que possam conter o viés deficitário de um governante.

A princípio, a década de 1990 foi marcada pela existência de regras mais rígidas e que focavam em metas anuais de curto prazo para o resultado fiscal. Posteriormente, em meados dos anos 2000, uma nova corrente baseada em uma série de trabalhos fomentavam o aprimoramento das regras fiscais combinando investimento com sustentabilidade fiscal a médio prazo. Entretanto, com a crise internacional de 2008, incentivou-se um debate teórico e empírico para uma flexibilização das regras que acomodasse os efeitos de ciclos econômicos e as variações fiscais. Nesse sentido, o debate girava em torno de críticas as características da anterior por não permitir ajustes a distorções exógenas das despesas públicas, além de minimizar a transparência, abrindo espaço para possíveis manipulações fiscais (Orair, 2016).

Nessa perspectiva, vários países (União Europeia, Chile e Suiça) realizaram reformas institucionais e serviram como modelo de experiência (Gobetti, 2014). Assim, as regras fiscais foram disseminadas pelo mundo na tentativa de assegurar uma disciplina fiscal e sustentabilidade do endividamento público. Ao que pese uma diversidade de conceitos quanto ao tema das regras fiscais, estas estão comumente classificadas como ideal, flexível e rígida. A primeira reforça o objetivo de alinhar sustentabilidade econômica com flexibilidade de acontecimentos fiscais e políticas eficientes. A flexível analisa os efeitos de um ciclo econômico visando amenizar rigidez de metas fiscais em detrimento de investimentos públicos. Por fim, as rígidas possuem características de metas legalmente impostas ou vinculada às opções do governo (Von Hagen \& Wolff, 2006; Menezes \& Tonedo Junior, 2006; Gobetti, 2014; Lledó et al., 2017; Gonçalves, 2018).

Para Souza (2008), não há um consenso quanto ao modelo de regra fiscal ideal, já que tais regras se diferem de país a país. No entanto, há unanimidade quanto ao objetivo principal que é o de servir como mecanismo para a redução da discricionariedade dos governantes nas tomadas de decisões restaurando a sustentabilidade fiscal. No Brasil, as regras fiscais estão agrupadas em um conjunto com diferentes características como, por exemplo, a regra de ouro, que constitucionalmente tem como objetivo evitar o aumento do endividamento público para financiar as despesas correntes. As outras regras, que podem ser 
encontradas na LRF, visam promover um equilíbrio fiscal das contas públicas reforçando a necessidade de um pensamento austero e responsável.

Sendo assim, a adoção de regras fiscais reduz o grau de liberdade de um gestor e cumpre seu papel à medida que determina restrições dos gastos, como no caso daqueles preferidos pelo poder partidário em atuação. Além disso, permite que o dispêndio do recurso público ocorra em favorecimento à sociedade em geral (Montes \& Alves, 2012). A esse respeito, os gastos públicos encontram-se categorizados pela literatura como a interferência econômica do Estado na aplicação de recursos e prestação de serviços previamente definidos no orçamento. Do mesmo modo, correspondem as preferências alocativas do governo e possibilitam entender a dinâmica da execução das políticas públicas na distribuição e redistribuição de recursos. Os estudos a respeito dos gastos e recursos públicos passaram a se destacar como fontes de pesquisa para as ciências econômicas e de finanças (Rezende, 2008; Bogoni, Hein, \& Beuren, 2011; Coate \& Knigt, 2011 ; Videira \& Matos, 2011; Silva, Ferreira, Braga, \& Abrantes, 2012; Soares, Clemente, Freire \& Scarpin, 2016).

Conforme taxonomia preconizada no estudo de Rezende (1997), os gastos podem ser classificados de acordo com a preferência alocativa. A primeira categoria que representa os gastos relacionados à atividade econômica, na qual o governo assume o papel de intervenção ou regulador, são classificados como econômicos. A segunda categoria é a dos gastos mínimos e correspondem àqueles pelos quais o governo detém domínio exclusivo. Por fim, a categoria dos gastos sociais representam a parcela do gasto aplicado pelo governo na provisão de bens e serviços de caráter meritório ou quase-público.

Sakurai (2009) apresenta que algumas funções orçamentárias passam a ser mais priorizadas em decorrência das preferências administrativas ou de opções partidárias. Entre essas preferências estão os gastos sociais. $\bigcirc$ financiamento de alguns gastos sociais brasileiros (ex: educação, saúde e seguridade social) é obrigatório e segue o princípio da vinculação. Para Salvador (2016), isso se caracteriza como "engessamento" do orçamento público, pois, reduz a discricionariedade do gestor e proibi a execução de contingências para um superávit. A vinculação assegura que os governantes realizem a execução mínima dos gastos minimizando a predominância da ideologia política do governante.

Dentre os gastos com maiores esforços para garantir fontes de financiamento efetivos e específicos, estão a educação e saúde, pois, possuem fontes vinculadas. A rigidez também pode ser encontrada pelos limites de endividamento preconizados pela LRF e neste caso se encontram os gastos com investimentos. Todavia, Neduziak e Correa (2018) apresentam que a rigidez do financiamento dos gastos não abarca a todos os gastos sociais, como assistência social, cultura e desenvolvimento, e habitação. Isto permite que cada governante os execute a partir de suas preferências político-partidárias.

Nesse mesmo contexto, há uma discricionariedade dos governantes no comportamento fiscal para os gastos públicos não vinculados. Estudos como o de Orair e Siqueira (2016) buscaram identificar determinantes para a aplicação desses recursos. Posteriormente, Orair e Siqueira (2018) identificaram que o volume destinado aos investimentos públicos e às outras despesas está relacionado às orientações das políticas públicas e às prioridades dedicadas por cada governo. 
Gastos Sociais e Accounting Gimmicks: Uma Percepção dos Ciclos Políticos Eleitorais nos Municípios do Centro-Oeste Brasileiro

Entretanto, tais opções, no caso brasileiro, deveriam obedecer ao conjunto de regras fiscais estabelecidas.

\subsection{Ciclos Políticos Eleitorais}

A realidade democrática que afeta o mundo trouxe consigo um paradoxo aos representantes eleitos que tomam decisão sobre a política fiscal e econômica do local. Tais representantes enfrentam a dificuldade em conciliar uma execução de políticas públicas voltadas à sociedade ou de manter fidelidade ao seu eleitorado. Dessa forma, emergiram duas correntes teóricas opostas que buscam explicar as influências das decisões políticas no contexto econômico: a Teoria dos Ciclos Políticos Eleitorais e a Teoria do Controle Político.

A Teoria dos Ciclos Políticos Eleitorais propaga os esforços que os agentes eleitos realizam para melhorar seu desempenho de forma a garantir sua permanência no poder da administração pública. A discussão teórica e empírica desta abordagem levou às diversas variações quanto ao nome propriamente dito, porém, a centralidade do fenômeno continuou o mesmo (Milesi-Ferreti, Perotti \& Rostagno, 2002; Silva, 2018). O pressuposto teórico mais relacionado ao assunto remete ao estudo seminal de Downs (1957). Para o autor, a ação do governo ocorre de forma racional e visa especificamente a maximização de seu desempenho político-eleitoral, da mesma forma que o setor privado trabalha com a teoria de uma maximização de lucros e permanência monopólica do poder.

Nesse contexto, Sakurai (2009) define Ciclos Políticos como os fatores influenciadores da política em relação ao comportamento econômico de um local. As duas escolas iniciais da Teoria dos Ciclos Políticos Eleitorais utilizaram dos pressupostos da Teoria dos Ciclos Econômicos para a justificativa de tais influências. A primeira abordagem apresentada por Nordhaus (1975) considera que a ação política está baseada em uma expectativa adaptativa e permeada de incentivos oportunistas visando a probabilidade de permanência no poder. A segunda abordagem voltada à expectativa racional foi defendida por Rogoff e Sibert (1986) e considera que as ações políticas estão em função de uma assimetria de informações entre os representantes e o eleitorado.

Em uma segunda fase de construção do pensamento teórico dessa teoria surgiu a ideia de que as influências das eleições nos ciclos econômicos também se relacionavam à política partidária ou ideológica do governante. $\bigcirc$ trabalho de Alesina (1987) é considerado como referência básica para esse novo pressuposto. Para a autora, a maximização dos ciclos políticos ocorre em situações pelas quais os eleitores são influenciados pelas incertezas que podem ocorrer após a vitória de um novo partido na corrida eleitoral.

Para Simonassi e Cândido Junior (2008), a existência de uma corrente teórica dos Ciclos Políticos eleitorais que prevê um comportamento oportunista ou partidário durante as eleições é contraposta ao surgimento de outra abordagem: a Teoria do Controle Político. Preconizada por Barro (1973) e Ferejohn (1986), essa corrente teórica apresenta as eleições como um mecanismo capaz de ratificar a responsabilização dos políticos. Está relacionada aos modelos pelos quais existe uma assimetria entre principal e agente. Neste caso, os agentes são os políticos e não possuem informações sobre o interesse do 
eleitorado que se tornam o principal. Dessa forma, ao buscar continuar os ciclos políticos eleitorais, o governante passa a ter um comportamento alinhado ao interesse do eleitor e minimiza o oportunismo.

Nakaguma e Bender (2010) defendem que as abordagens da Teoria dos Ciclos Políticos Eleitorais e a Teoria do Controle Político embora apresentem pressupostos contraditórios agem de maneira a se complementarem. Cada abordagem trata de maneira distinta a relação do representante com o eleitorado. Para a modelo de ciclos políticos, os eleitores tomam a preferência por representantes pautados em competência e tais ciclos servem como mecanismos de sinalização para demostrar a competência adquirida. Já para a abordagem do controle político eleitoral, a permanência no cargo pode gerar tendências ao oportunismo e as eleições servem para que os eleitores sinalizem o controle em suas mãos.

\subsection{Desenvolvimento das Hipóteses}

A responsabilidade dos estados e municípios em oferecer o bem-estar social retrata a visibilidade do desempenho fiscal do governante. A rigidez fiscal pode agir como mecanismo que afeta os interesses oportunistas e afetar positivamente nas decisões fiscais (Drazen e Eslava, 2005). Em virtude do cumprimento de tais gastos rígidos e pela sinalização de competência administrativa aos seus eleitores, os governantes tendem a manipular a situação fiscal a partir de alterações nos gastos públicos. Mediante ao exposto, tem-se a hipótese $\left(H_{1}\right)$ de que há uma relação positiva entre regras fiscais rígidas e as práticas de accounting gimmicks.

Conforme Macedo e Corbari (2009), as práticas de um sistema baseado somente nas transferências de um ente central geram uma tendência nos municípios de gastos excessivos e sucessivos déficits, impulsionando maior endividamento. Nesse sentido, os municípios que possuem um alto grau de dependência são levados a um baixo esforço fiscal próprio. Dessa forma, existe a possibilidade de maximizarem o oportunismo fiscal e a utilização de truques contábeis para a manutenção dessas transferências. Sendo assim, presume-se a hipótese $\left(\mathrm{H}_{2}\right)$ de que há uma relação positiva entre a dependência financeira do município e as práticas de accounting gimmicks.

Os excedentes de despesa inscritos nas contas de restos a pagar são considerados como artifícios legais de escape para a manutenção de superávits preservando resultados de disciplina fiscal (Souza, 2013). Os restos a pagar são os mecanismos com maior tendência a sofrerem as manipulações alocativas do gestor, dado que os seus saldos não entram nos resultados primários. Deste modo, surge a hipótese $\left(\mathrm{H}_{3}\right)$ que há uma relação positiva entre as contas de restos a pagar e as práticas de accounting gimmicks.

Os entes federativos devem exercer um equilíbrio entre demanda social e investimento de gasto público. Em certas ocasiões, o aumento de gastos de um município pode estar pautado em políticas pelas quais os governantes adotem artifícios contábeis na mesma medida que reduzem os gastos no setor. Para uma competição fiscal, determinado município pode imitar o padrão de gastos de seu vizinho sinalizando um bom desempenho para seu eleitorado (Videira \& Mattos, 2011 ). A hipótese $\left(H_{4}\right)$ de que há uma relação positiva entre a interação espacial 
Gastos Sociais e Accounting Gimmicks: Uma Percepção dos Ciclos Políticos Eleitorais nos Municípios do Centro-Oeste Brasileiro

dos municípios e as práticas de accounting gimmicks está baseada nas atitudes do governante para gerar uma valorização do seu desempenho a uma parcela de sua população.

Os municípios brasileiros são conhecidos por uma constante permanência de poder, seja pela reeleição ou sucessão de aliados (Sakurai, 2009). O desempenho político tem sido endossado, em alguns casos, por suavização de resultados fiscais. Com isso, presume-se a hipótese $\left(\mathrm{H}_{5}\right)$ de que há uma relação positiva do ciclo político eleitoral com as práticas de accounting gimmicks. Nesse sentido, Nakaguma e Bender (2006) apresentaram que as mudanças que ocorreram após a promulgação da lei que regularizou a reeleição nos entes federativos brasileiros, possibilitou um aumento na tendência de manipulações fiscais visando o oportunismo político em períodos eleitorais. Dessa maneira, a hipótese $\left(\mathrm{H}_{6}\right)$ na qual há uma relação positiva de comportamento oportunista para reeleição com as práticas de accounting gimmicks deve ser analisada. Gámez e lbarra-Yúnez (2009) atribuem isso a ciclos políticos oportunistas nos quais os governantes utilizam desses próprios instrumentos para conseguir sucesso no pleito eleitoral.

\section{METODOLOGIA}

A pesquisa se caracteriza como descritiva-explicativa. Foram empregadas análises documentais em artigos, livros, legislação, relatórios e demonstrações contábeis dos entes investigados. Além disso, foi utilizada a estatística descritiva e inferencial, por meio de regressão logística binomial. Em relação ao método, destaca-se o quantitativo, através da análise econométrica dos dados, por meio de estimadores não lineares (Gujarati \& Porter, 2011).

A investigação contempla os 466 municípios da região Centro-Oeste, conforme dados do Instituto Brasileiro de Geografia e Estatística (IBGE), divididos em 246 municípios goianos, 141 mato-grossenses e 79 sul mato-grossenses, além do Distrito Federal. Foi criado um painel não balanceado com dados anuais do período de 2004 a 2017, compreendendo 4 ciclos políticos - 2004, 2008, 2012 e 2016. O período da amostra se deu em virtude do início de vigência da Lei Complementar n. ${ }^{\circ}$ 101, de 4 de maio de 2000 (Brasil, 2000) e da Resolução do Senado Federal n. ${ }^{\circ}$ 40, de 20 de dezembro de 2001.

As informações das contas regionais e das finanças públicas de cada município foram coletadas na base das Finanças Públicas do Brasil (Finbra) e no Sistema de Informações Contábeis e Fiscais do Setor Público Brasileiro (Siconfi). Os dados foram retirados do balanço patrimonial, do balanço orçamentário, da demonstração de variações patrimoniais, bem como do relatório resumido de execução orçamentária (RREO) e o relatório de Gestão Fiscal (RGF). Os demais dados, como quantidade de habitantes, PIB municipal, índices de IPCA e informações das eleições foram selecionados: (i) no IBGE; (ii) no Instituto de Pesquisas Econômica Aplicada - Ipea; (iii) no Banco Central do Brasil - Bacen; (iv) no Sistema de Informações sobre Orçamentos Públicos em Educação - SIOPE; (v) no Departamento de informática do SUS - Datasus; e (vi) no Tribunal Superior Eleitoral (TSE).

Os municípios que não possuíam dados na base do STN foram considerados como valores ausentes. A partir do cálculo da distância Mahalanobis foram 
encontrados casos com outliers multivariados, sendo excluídos da amostra. Dentre esses casos, foi detectada a existência de uma subamostra no conjunto de dados do Distrito Federal. Dessa forma, o número de observações finais foi de 5517.

Para a verificação dos níveis de SFA em cada município, observou-se o entendimento proposto pelo modelo estudado por Reischmann (2015). Para o autor, a variação da dívida (B) em um período t deve representar o mesmo valor ao déficit $(D)$ do período t. O resultado do nível da dívida no período $t$ corresponde aos valores do déficit acumulado somados ao nível da dívida. Caso haja uma não conformidade nesses resultados é possível a inferência de accounting gimmicks. A equação 1 representa o entendimento apresentado por Reischmann (2015).

$$
B_{t}-B_{t-1}=D_{t}+S F A_{t}
$$

Paralelamente, o estudo de Silva (2018) que ao propor um modelo adaptado à realidade brasileira apresentou as variações do SFA ponderado pela $\mathrm{RCL}$, serviu como base também para o desenvolvimento inicial da variável dependente desse estudo. No que se refere a transformação da variável foram utilizados procedimentos semelhantes ao praticado por Freire, Monteiro, Vieira, Santos e Freire Filho (2007). Os procedimentos se utilizam de inferências matemáticas a partir do cálculo da média e desvio-padrão do município i no período $t+n$. Primeiramente a variável utilizada como base (sfa_rcl) foi padronizada tendendo a uma distribuição normal. A equação 2 demonstra tal padronização, em que, $z_{s f a \_r c l} \sim N(0,1)$.

$$
\mathrm{Z}_{s f a_{-} r c l_{i, t}}=\frac{s f a_{-} r c l_{i, t}-\bar{X}}{\sigma}
$$

O resultado da equação fez emergir uma nova variável denominada AccountG. Para a categorização da variável nos atributos de 0 e 1 foi considerado a premissa de que municípios que apresentam o resultado da conta de SFA igual a zero não demonstram o uso de accounting gimmicks. Logo, para os valores diferente de zero, cujo valor representa variações positivas ou negativas, ocorre a presença do SFA com possibilidade de verificação dessas práticas (Alt \& Lassen, 2006).

Em se tratando de uma amostra onde o número de municípios que apresentaram SFA igual a zero foi muito pequeno, subtende-se a existência de qualquer margem de erro já que os dados utilizados para a pesquisa podem conter alguma imprecisão contábil, principalmente em virtude das transformações do sistema contábil do setor público ocorrido com a convergência às normas internacionais. Sendo assim, foi considerada a margem de erro amostral (e) no processo de classificação do município e adesão a variável, conforme a equação 3. 


$$
e=Z_{\propto / 2} \pm \sqrt{\frac{p(1-p)}{n}} \cong \frac{1}{n}
$$

Em que $z$ representa o valor da tabela $Z$ de confiabilidade definida para $95 \%$ de confiança; $P$ representa a proporção estimada (usualmente utilizada do valor de 0.5) e n é o tamanho da amostra.

Adicionalmente, foram consideradas as variáveis explicativas: (i) gastos per capta com educação, gastos per capta com saúde, gastos per capta com habitação e gastos per capta com investimento, (ii) restos a pagar processados e restos a pagar não processados, (iii) dependência financeira, (iv) inflação, (v) centralidade, (vi) tamanho, (vii) ano de eleição, ano anterior à eleição, ano após a eleição, (viii) ideologia, e (ix) oportunismo. Na Tabela 1 são apresentadas as informações do resumo quanto à descrição e referências das variáveis utilizadas para a composição do objeto de estudo.

\section{Tabela 1}

Resumo quanto à descrição e fundamentação das variáveis do estudo

Variável Dependente

AccountG

\section{Proxy}

Representa a variável binária na qual

1 está atribuído a presença de accounting gimmicks e 0 em casos contrários a partir da existência do SFA ponderado pela/RCL do município i no período ${ }^{\dagger}$

Variável
Independente

Representa o saldo das despesas correntes per capta com a função educação do município i no período $t$

Representa o saldo das despesas correntes per capta com a função saúde do município i no período † Representa o saldo das despesas per capta com a função habitação do município i no período ${ }^{\dagger}$

Representa o saldo das despesas per capta na função investimentos do município i no período $t$

Logaritmo natural do saldo final da contas de Restos a Pagar Processados no munícipio $i$, no período $t$.

Logaritmo natural do Saldo final da conta de Restos a Pagar não

Lnrpnp processados no munícipio i, no período $t$.

\section{Fundamentação Teórica}

Exploratória a partir de estudos

como Buti et al. (2007);

Clémenceau e Soguel (2017), Von Hagen e Wolff (2006); Reischman (2015); Silva (2018); Weber (2012)

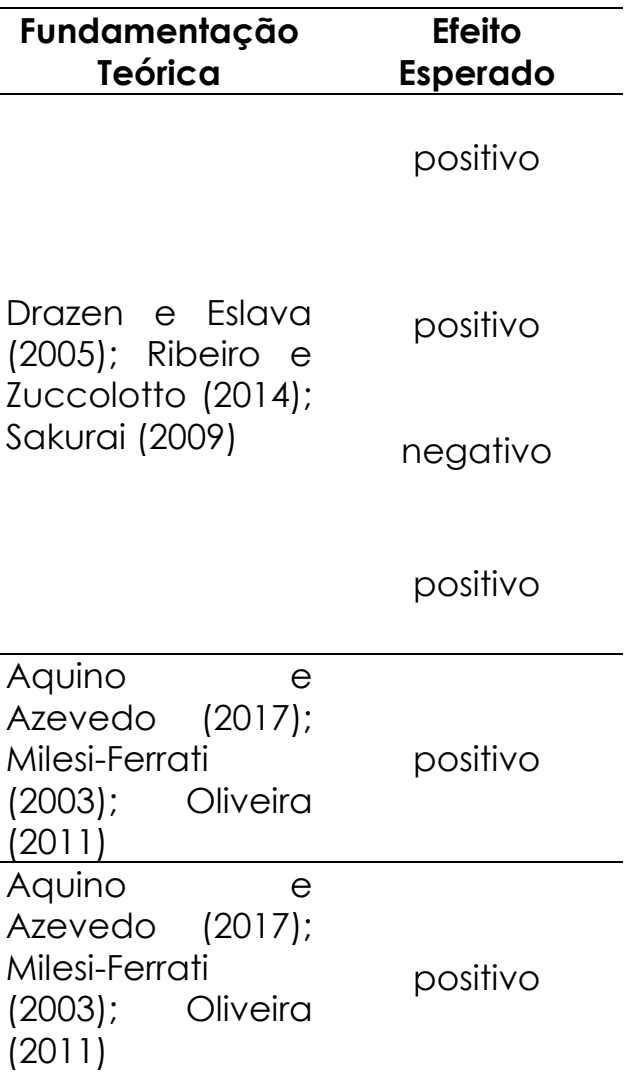




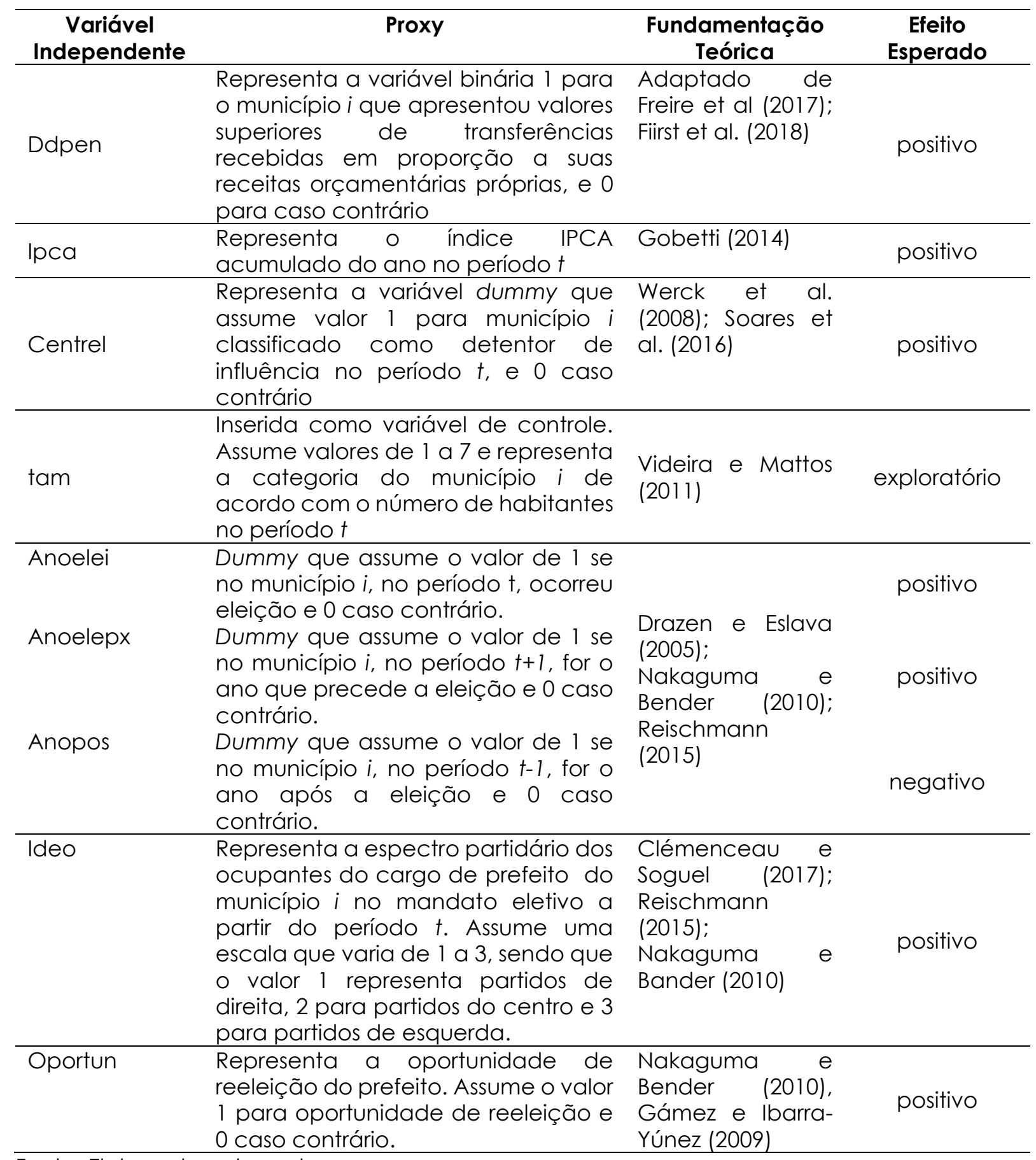

Fonte: Elaborado pelos autores

Nota: Valores das contas públicas deflacionados pela metodologia utilizada na calculadora do Banco Central do Brasil.

O sinal positivo esperado para os gastos sociais da educação e saúde corresponde a tendência de prática do gestor para o cumprimento da rigidez fiscal. É importante destacar que dentre os gastos sociais não foram selecionados os gastos com seguridade e previdência devido à falta de informações para esta função na maioria dos municípios. Por outro lado, o sinal negativo é esperado no caso da função habitação por se tratar de uma preferência alocativa do gestor sem uma rigidez fiscal. Entretanto, a função investimento está inserida, pois, possui um grau de rigidez de aplicação nos limites de endividamento, além do mais, são gastos comumente utilizados no processo decisório governamental com razões 
oportunistas, principalmente eleitorais (Drazen \& Eslava, 2005; Orair \& Siqueira, 2018).

Espera-se um sinal positivo para a dependência financeira (ddpen), pois, o grau de dependência não permite uma liberdade fiscal do gestor (Fiirst et al, 2018). A princípio, a variável foi calculada a partir de indicador proposto por Freire et al. (2007) no qual a receita própria menos as transferências governamentais em proporção a receita total indicava a dependência financeira do local. 0 indicador apresentou um número mínimo de municípios com dependência inferior a 90\%. Dessa forma, optou-se pela escolha de identificar dicotomicamente, os municípios em que os valores das transferências governamentais recebidas superam os valores das receitas orçamentárias próprias.

Em suma, a variável dependente do estudo passa a assumir uma característica qualitativa de natureza binária ou dicotômica, sendo detectada mais comumente por modelo de regressão logit. Corroborando com a ideia de Goto e Yamamoto (2018) de que é difícil a compreensão dos mecanismos e da causalidade de truques contábeis, buscou-se instituir um modelo que apresente a probabilidade de ocorrência. A regressão foi realizada com o auxílio do software estatístico Stata 13. A equação 5 apresenta o modelo do estudo:

\section{AccountG}

$=\overline{1+\mathbf{e}^{\beta_{0}+\beta_{1} \text { Gastos }_{i t}+\beta_{2} \operatorname{lnIrpp}_{\text {it }}+\beta_{3} \operatorname{lnrpnp}_{\text {it }}+\beta_{4} \text { ddpen }_{\text {it }}+\beta_{5} \text { Centrel }_{\text {it }}+\beta_{6} \text { Tam }_{\text {it }}+\beta_{7} \text { Elei }_{i t}+\beta_{8} \text { Oport }_{\text {it }}+\beta_{9} \text { ipca }} \text { it }}$

\section{ANÁLISE DOS RESULTADOS}

Das 5517 observações do estudo, 1283 (23,26\%) corresponderam a observações nas quais os municípios não apresentaram ocorrência de accounting gimmicks. O valor de observações nas quais os municípios apresentaram a ocorrência de accounting gimmicks é de 4234, o que corresponde a $76.74 \%$ do total das observações.

Foram realizados testes estatísticos para verificar se as médias entre os grupos possuíam igualdade estatística. No caso das variáveis qualitativas, o teste do qui-quadrado (Ch2) foi utilizado, o qual constatou que não houve correlação significativa entre as médias dos grupos das variáveis centrel, tam, ideo e oport em relação às práticas de accounting gimmicks. Em se tratando das quantitativas, o teste não paramétrico de Wilcoxon verificou que as variáveis educ_cap, Inrpnp, centrel, tam, ideo e oport não foram estatisticamente significantes. Os resultados das análises estatísticas descritivas das variáveis utilizadas no estudo se encontram na Tabela 2. 
Tabela 2

Estatísticas Descritivas das variáveis utilizadas no modelo

\begin{tabular}{lllllllll}
\multicolumn{1}{c}{ Variável } & Obs & Média & Dev. Padrão & Min & Max & Chi2 & $\begin{array}{c}\text { Teste de } \\
\text { Wilcoxon }\end{array}$ \\
\hline educ_pcap & 5517 & 920.0966 & 750.1658 & 0 & 8852.838 & & 0.7152 \\
saud_pcap & 5517 & 680.9582 & 391.9506 & 0 & 4855.081 & & 0.0493 \\
hab_pcap & 5517 & 260.3745 & 251.8519 & 0 & 5128.234 & & 0.0058 \\
inv_pcap & 5517 & 302.8707 & 392.5635 & 0 & 11718.74 & & 0.0000 \\
Inrpp & 5517 & 11.47592 & 4.37271 & 0 & 18.70377 & & 0.0016 \\
Inrpnp & 5517 & 6.736116 & 6.632249 & 0 & 19.20128 & & 0.2465 \\
ipca & 5517 & 5.732998 & 1.672952 & 2.95 & 10.67 & & 0.0000 \\
ddpen & 5517 & 0.235454 & 0.424321 & 0 & 1 & 0.016 & 0.0160 \\
centrel & 5517 & 0.171289 & 0.376795 & 0 & 1 & 0.095 & 0.0946 \\
tam & 5466 & 2.425357 & 1.308012 & 1 & 7 & 0.252 & 0.0999 \\
anoelei & 5517 & 0.275875 & 0.446994 & 0 & 1 & 0.000 & 0.0002 \\
anoelepx & 5517 & 0.210803 & 0.407916 & 0 & 1 & 0.000 & 0.0000 \\
anopos & 5517 & 0.286569 & 0.452199 & 0 & 1 & 0.000 & 0.0000 \\
ideo & 5444 & 1.796841 & 0.749953 & 1 & 3 & 0.277 & 0.1717 \\
oport & 5473 & 0.799562 & 0.400365 & 0 & 1 & 0.459 & 0.4592 \\
\hline
\end{tabular}

Fonte: Elaborada pelos autores

Foram realizados testes para detecção de multicolinearidade pelo VIF e tolerância. Os valores encontrados permitiram a inferência de ausência de multicolinearidade já que para as variáveis o valor de VIF foram menores que 10. Os resultados do qui-quadrado (Ch2) para máximo verossimilhança apresentam as estatísticas de ajustes de modelo com um nível de significância abaixo de 1\%. Essa suposição está relacionada a fato de que as variáveis introduzidas ao modelo provocam um impacto significativo na previsão da probabilidade de ocorrência do evento (Hair et al., 2009).

Dessa forma, o modelo com a inclusão de todos os gastos foi utilizado para testar as hipóteses da pesquisa, o que constatou que a probabilidade de ocorrência da accounting gimmicks deve ser analisada de uma forma global, não sendo possível no momento a decomposição dos gastos. Pelo teste de Hausman com p-valor $(0,0019)$ rejeita-se a hipótese de que o modelo para efeitos aleatórios é mais adequado. Assim, optou-se pelo modelo de regressão logística em um painel de efeitos fixos. A Tabela 3 apresenta os resultados obtidos dos coeficientes e o fator de chance (odds ratio) para o modelo logit de efeitos fixos. 
Gastos Sociais e Accounting Gimmicks: Uma Percepção dos Ciclos Políticos Eleitorais nos Municípios do Centro-Oeste Brasileiro

\section{Tabela 3}

Modelo de Efeitos Fixos para AccountG

\begin{tabular}{|c|c|c|c|c|c|c|c|}
\hline accountG & Coef. & OR & Std. Err. & z & $P>z$ & [95\% Conf. & Interval] \\
\hline educ_pcap & 0.0002222 & 1.000222 & $5.65 \mathrm{E}-05$ & 3.930 & $0.000 * * *$ & 0.0001115 & 0.000333 \\
\hline saud_pcap & -0.0005245 & 0.9994756 & 0.000143 & -3.670 & $0.000^{* * *}$ & -0.0008047 & -0.0002443 \\
\hline hab_pcap & $-7.330 \mathrm{E}-08$ & 0.9999999 & 0.000205 & 0.000 & 1.000 & -0.0004015 & 0.0004013 \\
\hline inv_pcap & 0.0002935 & 1.000294 & 0.000146 & 2.010 & $0.044^{*}$ & 7.53E-06 & 0.0005794 \\
\hline Inrpp & 0.0159689 & 1.016097 & 0.009101 & 1.750 & 0.079 & -0.0018683 & 0.0338062 \\
\hline Inrpnp & -0.0056679 & 0.9943481 & 0.006477 & -0.880 & 0.382 & -0.0183632 & 0.0070274 \\
\hline ipca & -0.1104281 & 0.8954507 & 0.02349 & -4.700 & $0.000 * * *$ & -0.1564673 & -0.0643888 \\
\hline ipca & -0.1104281 & 0.8954507 & 0.02349 & -4.700 & $0.000^{* * *}$ & -0.1564673 & -0.0643888 \\
\hline $\begin{array}{l}\text { ddpen } \\
\text { centrel } \\
\text { tam }\end{array}$ & $\begin{array}{l}0.3033229 \\
0\end{array}$ & $\begin{array}{l}1.354352 \\
\text { (omitted) }\end{array}$ & $\begin{array}{l}0.103633 \\
\text { (omitted) }\end{array}$ & 2.930 & $0.003^{* *}$ & 0.1002061 & 0.5064398 \\
\hline 2 & 0.2638401 & 1.30192 & 0.203859 & 1.290 & 0.196 & -0.1357155 & 0.6633958 \\
\hline 3 & 0.3904817 & 1.477692 & 0.261862 & 1.490 & 0.136 & -0.122759 & 0.9037224 \\
\hline 4 & -0.0731624 & 0.9294498 & 0.327246 & -0.220 & 0.823 & -0.7145532 & 0.5682283 \\
\hline 5 & 0.1500176 & 1.161855 & 0.636617 & 0.240 & 0.814 & -1.097729 & 1.397764 \\
\hline 6 & -2.158676 & 0.1154779 & 1.067997 & -2.020 & $0.043^{*}$ & -4.251911 & -0.0654415 \\
\hline 7 & 0 & (empty) & (empty) & & & & \\
\hline anoelei & -0.5257481 & 0.591113 & 0.115648 & -4.550 & $0.000 * * *$ & -0.7524131 & -0.299083 \\
\hline anoelepx & -1.168552 & 0.3108167 & 0.118835 & -9.830 & $0.000^{* * *}$ & -1.401464 & -0.9356398 \\
\hline anopos & -1.238332 & 0.2898673 & 0.114348 & -10.830 & $0.000^{* * *}$ & -1.46245 & -1.014214 \\
\hline ideo & - & - & - & - & - & - & - \\
\hline 2 & -0.0377477 & 0.9629559 & 0.096633 & -0.390 & 0.696 & -0.2271439 & 0.1516485 \\
\hline 3 & 0.0656351 & 1.067837 & 0.12171 & 0.540 & 0.590 & -0.1729114 & 0.3041816 \\
\hline oport & 0.1848112 & 1.202991 & 0.094281 & 1.960 & $0.050^{*}$ & 0.0000232 & 0.3695993 \\
\hline LR Chi2 & 281.31 & & & & $0,000^{* * *}$ & & \\
\hline N & 5063 & & & & & & \\
\hline Hausman Chi2 & 60.12 & & & & 0,0000 & & \\
\hline
\end{tabular}

Fonte: Elaborada pelos autores

Nota: $\mathrm{p}<0.05 ;{ }^{* *} \mathrm{p}<0.01 ;{ }^{* * *} \mathrm{p}<0.001$. As variáveis centrel e a categoria 7 da variável tam foram omitidas devido a nenhuma variação dentro do grupo

As variáveis explicativas educ_pcap, saud_pcap, ipca, anoelei, anoelepx e anopos apresentaram nível de significância estatisticamente diferente de zero a menos 1\%. Por outro lado, as variável inv_pcap, ddpen e oport apresentaram um nível de significância a 5\%. Em uma abordagem menos conservadora e implicando na ocorrência do erro tipo II, pode-se considerar a significância estática da variável Inrpp a 10\%. A variável tam obteve nível de significância estatística somente para a categoria 6 que corresponde a faixa populacional de municípios de 100.001 até 500.000 habitantes. Sendo assim, tais variáveis exercem efeito na probabilidade de ocorrência da ocorrência de accounting gimmicks.

É importante destacar que a análise das observações geradas pela regressão logística deve estar atenta ao valor dos odds ratio, doravante chamados de fator de chance. Enquanto os coeficientes estimados indicam a direção para a mudança em relação à variável dependente, os odds expressam a razão probabilística do evento ocorrer ou não. Para o cálculo dessa 
probabilidade foram consideradas as informações do estudo de Corrar, Paulo e Dias Filho (2009, p. 313).

\subsection{Gastos Públicos}

A hipótese 1 testou a relação positiva entre as regras fiscais rígidas e as práticas de accounting gimmicks. Para isso, foram analisados os gastos públicos como detentores da rigidez fiscal dos municípios brasileiros (educação, saúde e investimento) e adicionalmente gastos que não expressam tal rigidez (habitação). No caso de gastos com investimento, embora não classificado como sociais, a inclusão ao modelo visava a identificação de gastos comumente utilizados como oportunismo fiscal para eleição. Os coeficientes se apresentaram relativamente baixos $(0,000022$ para educ_pcap, de $-0,0005245$ para saud_pcap, de -7,330E-08 para hab_pcap e de 0,002935 para inv_pcap) indicando um efeito marginal inferior ao esperado.

Com um nível de significância estatística a menos de 1\%, a variável educ_pcap apresentou o sinal positivo esperado e permitiv a corroboração com o apresentado na hipótese 1. O resultado está corroborado por Arvate, Avelino e Lucinda (2008) ao enfatizarem que o aumento nos gastos em educação tende a determinar uma piora nos resultados fiscais primários, uma vez que a demanda utiliza de um número maior de recursos orçamentários. Dessa forma, o ambiente se torna propício ao gestor para a prática de accounting gimmicks na tentativa de melhorar seus resultados fiscais.

Embora com um nível de significância a menos de 1\%, a variável saud_pcap apresentou um sinal do coeficiente estimado contrário ao esperado estabelecendo uma relação inversa na presença de accounting gimmicks. Dessa forma, não foi possível corroborar com a hipótese 1 para esse tipo de gasto. 0 fator de chance $(0,9994)$ representa a probabilidade de uma redução de 0,013\% na chance de ocorrência de práticas de accounting gimmicks em caso de aumento nos gastos da função. A justificativa para este achado pode estar na determinação de outras variáveis para cada município. Uma delas está na eminência do serviço público oferecido por outros entes como Estado e União ou por relações de interação espacial, já que tais gastos são os que mais sofrem com essa interação (Soares et al., 2016). Assim, o gestor pode minimizar a preocupação com esse gasto em virtude da continuidade da prestação do serviço por outros. Consequentemente, a despesa ocorre de forma mínima ao exigido e não prejudicam resultados fiscais primários.

A variável hab_pcap apresentou o sinal esperado no estudo, porém não se apresentou estatisticamente significativa. Assim, não foi possível inferir resultados para a intenção precípua de entendimento da relação de gastos "não rígidos" com as práticas de accounting gimmicks. Já para a variável inv_pcap, o nível de significância foi de $5 \%$ e o sinal se apresentou como o esperado, corroborando com a hipótese 1. O resultado permitiu a inferência de que os gastos públicos com investimentos podem ser objetos de truques contábeis visando um oportunismo fiscal e sucessos eleitoreiros, como no exemplo da preferência pela construção de pontes e outras melhorias de infraestrutura que podem ser mais visíveis e mensuráveis, independente do aumento do déficit fiscal no município. Tais inferências são corroboradas na literatura por Sakurai (2009); Nakaguma e Bender (2010); Orair e Siqueira (2018). 
Nesse contexto, o fator de chance da probabilidade do evento, no caso dos gastos com investimento, também se apresentou baixo como o da variável do gasto com educação, representando uma probabilidade de menos de $1 \%$. A justificativa pode estar na eficiência da presença da LRF que impõe limites de endividamento aos entes federativos reforçando uma rigidez fiscal. Dessa maneira, os limites impostos são determinantes importantes para a escolha discricionária do gestor. Outro fato importante a se destacar para falhas na corroboração da hipótese pode ser inferido pelo fato levantado por Almeida e Sakurai (2018), onde a rigidez da utilização dos valores recebidos tem relação direta com as variáveis políticas.

\subsection{Dos Fatores Econômicos e Demais Fatores Fiscais}

Embora com o sinal diferente do esperado, a variável ipca apresentou nível de significância a menos de 1\%. Dessa forma, os resultados corroboram com a hipótese 1 e com a corrente que defende as regras fiscais rígidas como possíveis redutoras de taxas inflacionárias (Besley \& Case, 2003; Fatás \& Mihov, 2006; Arestis \& Sawyer, 2008; Sacchi \& Salotti, 2015). Por outro lado, ao observar o fator de chance $(0,89)$ da probabilidade de ocorrência sobre a variável dependente verifica-se uma probabilidade de $-2,75 \%$, ou seja, há uma diminuição na chance da ocorrência de accounting gimmicks em relação ao aumento de um ponto percentual da taxa de inflação. É sabido que efeitos econômicos são permeados de outras variáveis que podem ter sido suprimidas nesse modelo.

Os resultados apresentados pela variável ddpen permitem corroborar com a hipótese 2 inferindo que o nível de dependência financeira do município tem uma relação com as práticas de accounting gimmicks. Com um nível de significância estatística a 5\%, o coeficiente positivo apresentado na variável indica uma relação proporcional positiva com a variável dependente. Com fator de chance de 1,3545, a probabilidade na ocorrência de práticas de accounting gimmicks foi de $7,50 \%$ a mais no caso de municípios com alta dependência financeira. Os resultados corroboram com os achados de Dal-Ri e Correa (2019), os quais verificaram que os municípios dependentes de transferências governamentais utilizam delas para obter lucros eleitorais.

A hipótese 3 trata sobre a relação positiva entre as práticas de accounting gimmicks e as contas de restos a pagar foi corroborada ao se considerar para a variável Inrpp um critério menos conservador de nível de significância a 10\%. Dessa forma, pode-se verificar uma relação estatística significativa com a prática de accounting gimmicks. O fator de chance da variável que se apresenta como 1,0161 , corresponde a um aumento de chance na probabilidade de ocorrência de accounting gimmicks de $0,40 \%$ quando ocorrer uma variação positiva na variável. Os resultados corroboram com os achados de Alves et al. (2017) que apresentaram que a gestão dessa rubrica é algo recorrente para o setor público e que sua utilização pelos gestores serve como fonte de artifícios contábeis. Contudo, os resultados refutaram o poder de predição das contas de restos a pagar não processados (Inrnpp).

\subsection{Dos Fatores Demográficos}

Não foi possível corroborar a hipótese 4 de que as práticas de accounting 
gimmicks possuem relação positiva com a interação espacial com os municípios, pois a variável centrel não pôde ser analisada devido a não variância dentro do grupo. A variável tam foi adicionada ao modelo como variável de controle, porém não apresentou nível de significância estatística satisfatória na maioria das categorias indicadas. A única exceção está na categoria destinada aos municípios com mais de 100.000 até 500.000 habitantes que apresentou um coeficiente negativo estatisticamente significante com um fator de chance de 0.1154 . Esse fator representa que para cada aumento na categoria há uma redução de $-39,65 \%$ na probabilidade de ocorrência de accounting gimmicks.

\subsection{Dos Fatores Políticos}

A hipótese 5 que corresponde a relação positiva entre os ciclos políticos eleitorais e as práticas de accounting gimmicks foi parcialmente corroborada em virtude de variáveis que apresentaram sinais contrários ao esperado, como no caso das variáveis anoele e anoelepx. Embora com um nível de significância estatística a menos de 1\%, os sinais encontrados foram negativos. Dessa forma, tais resultados não corroboraram com a literatura acadêmica que relaciona os ciclos políticos como determinantes das práticas de manipulações fiscais. Com isso, o fator de chance da probabilidade apresentou efeito inverso à prática de accounting gimmicks sendo uma redução de $-12,84 \%$ e $-25,86 \%$, respectivamente, para a ocorrência de tais manipulações nos anos apresentados.

No entanto, é possível verificar uma corroboração parcial a partir da significância estatística da variável anopos, acrescentada para o fechamento total do ciclo eleitoral. A variável apresentou o sinal esperado no estudo (negativo) e um fator de chance de 0,2898, o que corresponde a probabilidade de $-27,53 \%$ de práticas de accounting gimmicks nos anos após a eleição. Os resultados da variável corroboram com o entendimento da literatura de ciclos políticos eleitorais que em anos após o pleito eleitoral, os governantes tendem a diminuir o seu comportamento oportunista e manipulações em virtude de dois determinantes: o primeiro relacionado ao ajuste fiscal recebido no governo anterior e o segundo pela proximidade com os resultados eleitorais, o que deixa o representante mais propenso a crítica e punições.

Da mesma forma, pode-se inferir que tais resultados se apresentaram mais alinhados a corrente teórica do Controle Eleitoral (Barro, 1973; Brambor \& Ceneviva, 2012; Duggan \& Martinelli, 2015). Pois, os governantes tendem a reduzir as práticas de accounting gimmicks visando permanência. Em vista disso, os resultados permitem inferir um fortalecimento de que os municípios têm assumido uma nova postura na política de controle social e eleitoral.

A corroboração parcial da hipótese 5 também se deu devido a variável categórica ideologia (ideo) não ter apresentado nível de significância estatístico. Infere-se assim que não há relação entre a prática de accounting gimmicks e a ideologia partidária. É sabido ainda que efeitos políticos são permeados de outras variáveis que podem ter sido suprimidas nesse modelo. Embora o resultado não tenha se apresentado significativo, os achados trazem uma contribuição a literatura ao apresentar que a existência do fator ideologia não determina a manipulação. 
A variável oport apresentou resultados de nível de significância estatístico a $5 \%$ corroborando com a hipótese 6 na qual as práticas de accounting gimmicks têm relação com o oportunismo político para reeleição. Com um sinal positivo esperado, o fator de chance de aproximadamente 1,2029 da variável representa um aumento de $4,61 \%$ na probabilidade de ocorrência de accounting gimmicks corroborando com os achados de Gámez e lbarra-Yúnez (2009) e Nakaguma e Bender (2006; 2010). Embora os resultados tenham apresentado um efeito contraditório com os ciclos políticos a partir da verificação pelos anos eleitorais, a significância estatística da variável oport corrobora com essa abordagem ao que diz respeito aos ciclos políticos que tendem a gerar maiores oportunismos nos representantes visando a manutenção no poder.

\subsection{Síntese do modelo}

Em suma, a adequação do modelo que representa a probabilidade de ocorrência de accounting gimmicks e o ajuste desse modelo podem ser observados na Tabela 4. Para Hair et al. (2009), a avaliação do ajuste do modelo também pode ocorrer a partir da comparação das suas predições entre os resultados. A tabela traz as classificações de acordo com a probabilidade que foram estimadas e os resultados observados da amostra. Os valores verdadeiros (true) apresentados correspondem a quantos foram eventos (ocorrência de accounting gimmicks -D) ou não foram eventos (não ocorrência de accounting gimmicks - D) para a variável accountG (Fávero \& Belfiore, 2017).

\section{Tabela 4}

Classificação para o Modelo do Estudo

\begin{tabular}{llll}
\hline & True & & \\
\hline Classificação & $D$ & $\sim D$ & Total \\
+ & 4111 & 1206 & 5317 \\
- & 15 & 15 & 30 \\
Total & 4126 & 1221 & 5347 \\
\hline
\end{tabular}

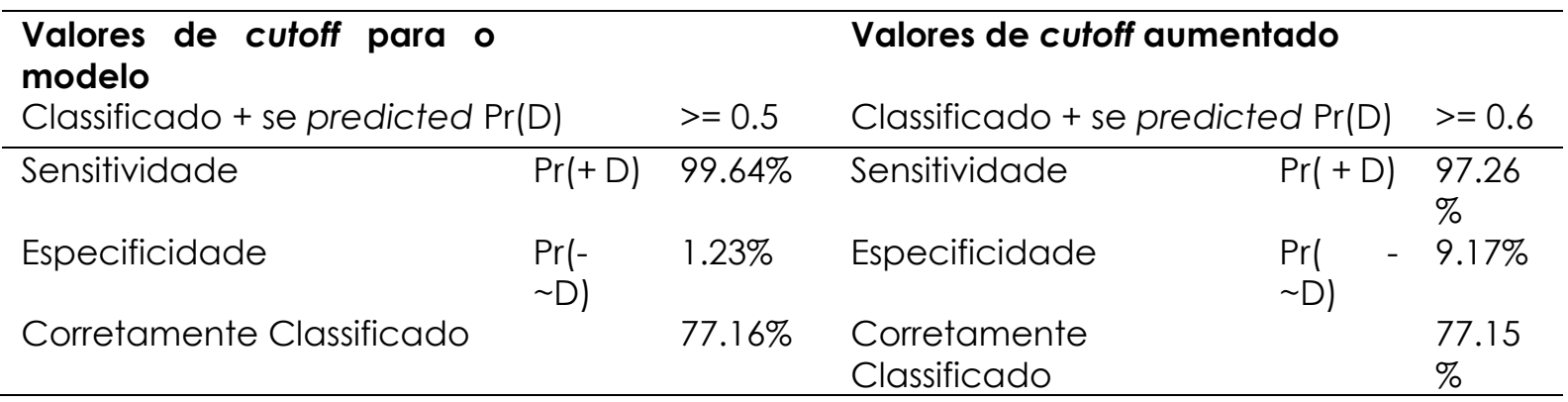

Fonte: Elaborada pelos autores

Nota: True D é definido como accountG != 0

De forma global, o modelo conseguiu classificar corretamente $77,16 \%$ da variância da ocorrência de eventos de accounting gimmicks nos municípios. Para Field (2009), o restante $(22,84 \%)$ representa variáveis ainda desconhecidas no modelo. A sensitividade de $99,64 \%$ representa a taxa de acerto daqueles que foram eventos. Por sua vez, a especificidade de 1,23\% refere-se a taxa de acerto dos que não foram eventos verdadeiros. É possível verificar que o aumento do cutoff para 0,6 ocasionará uma redução inexpressiva no modelo $(77,15 \%)$. Sendo 
assim, considerando a probabilidade de $100 \%$ de ocorrência, o resultado expressaria um ponto de corte entre 0,6 e 0,4 de ocorrência de accounting gimmicks.

Os resultados evidenciaram que as práticas comumente ocorrem em decorrência de determinantes amplamente experimentados pela literatura. Assim, infere-se o poder da contabilidade no setor público para acréscimo de qualidade fiscal e manutenção do bem-estar social. Diante da realidade dos municípios brasileiros como entes federativos que possuem maiores comportamentos oportunistas políticos, os achados da pesquisa acrescentam à literatura por meio da corroboração das hipóteses através de um modelo econométrico de que as variáveis utilizadas no estudo agem como determinantes relacionados às práticas de manipulação fiscal.

\section{CONSIDERAÇÕES FINAIS}

O presente estudo objetivou verificar em que extensão as práticas de accounting gimmicks afetam as políticas fiscais e a execução dos gastos sociais durante os ciclos políticos eleitorais. Foram analisados os 466 municípios da região Centro-Oeste brasileira no período de 2004 a 2017. Para isso, foi estimado um modelo de regressão logístico em painel de dados desbalanceado com variáveis identificadas pela literatura nacional e internacional de modo a explorar o fenômeno e responder o problema de pesquisa.

As variáveis utilizadas correspondem a fatores econômicos, fiscais, demográficos e políticos. A estimação do modelo permitiu corroborar parcialmente com a hipótese $\left(H_{1}\right)$ de que há uma relação positiva entre as regras fiscais rígidas e as práticas de accounting gimmicks. Os resultados apresentaram que os gastos sociais rígidos, como educação, e os gastos com limites rígidos de endividamento, como o de investimento são estatisticamente significantes em relação à probabilidade de ocorrência da accounting gimmicks. Entretanto, não foi possível corroborar tal fato aos gastos com saúde e habitação.

A hipótese $2\left(\mathrm{H}_{2}\right)$, que presumia a relação positiva entre a dependência financeira dos municípios com as práticas da accounting gimmicks, foi corroborada. Os resultados representaram que, em média, os municípios com maior índice de dependência financeira possuem a probabilidade de $7,5 \%$ a mais na ocorrência da prática de accounting gimmicks. A hipótese $3\left(\mathrm{H}_{3}\right)$ também foi corroborada. Tal hipótese buscava verificar a relação positiva das contas de restos a pagar dos municípios com as práticas de accounting gimmicks alinhando-se à literatura que identifica em tais contas uma maior tendência para manipulações contábeis por parte dos gestores. Inesperadamente, a hipótese $\left(\mathrm{H}_{4}\right)$ que presumia a relação positiva da interação espacial entre os municípios e as práticas de accounting gimmicks pelos gestores públicos foi refutada, pois, a variável que verificava a centralidade não se apresentou estatisticamente significativa.

Os resultados pelos quais se buscava uma relação positiva entre accounting gimmicks e o ciclo político eleitoral permitiram corroborar parcialmente com a hipótese $5\left(\mathrm{H}_{5}\right)$. As variáveis que identificaram o ano préeleitoral e o ano do pleito se apresentaram estatisticamente significativas, porém com sinais esperados contrários ao estudo. Tais resultados foram corroborados 
pela abordagem teórica do Controle Político. Corrobora-se também ao resultado, a significância da variável que identificou que no ano posterior a eleição, as práticas de accounting gimmicks tendem a sofrer uma redução de $27,53 \%$ de probabilidade de ocorrência. Isso é corroborado pela literatura dos ciclos políticos eleitorais ao identificar que nesses anos o governante está iniciando o seu ciclo eleitoral e em meio a ajustes fiscais, se preocupa com a proximidade da eleição e de que seus eleitores ainda estão com a memória mais ativa. Igualmente a hipótese $6\left(\mathrm{H}_{6}\right)$ foi corroborada ao verificar a relação positiva da accounting gimmicks com o comportamento oportunista pelo qual o gestor poderia utilizar de seu cargo para manipular resultados fiscais em favor de favorecimento eleitoral.

Vale ressaltar que os resultados encontrados no estudo se alinham as contradições entre as duas correntes literárias a respeito da rigidez das regras fiscais e existência de manipulações. De fato, as práticas de accounting gimmicks não podem ser somente direcionadas pela presença de regras fiscais rígidas. Sua presença está mais inclinada ao comportamento do governante em virtude de variáveis eleitorais. Ademais, é possível inferir que a presença de tais regras, como no caso da LRF, permitem maior sustentabilidade fiscal nos municípios e no caso de não inobservância desses limites, resultados prejudiciais podem assumir posições constates.

Este estudo trouxe uma contribuição a literatura ao apresentar uma exploração do fenômeno das práticas de manipulações contábeis ocorridas no contexto do setor público. O modelo econométrico proposto traz uma contribuição prática para a verificação de determinantes das práticas de accounting gimmicks nos governos subnacionais além de fornecer atributos ao poder da contabilidade na transparência fiscal e no bem-estar social.

Foram identificadas como limitação para a realização da pesquisa, a inexistência de dados disponíveis para todos os municípios. Além de uma base unificada para os dados das finanças públicas que proporcione um ajuste melhor no processo de coleta. Este fato impactou na melhora do número de observações para a pesquisa. Por conseguinte, para pesquisas futuras propõe-se a verificação do possível fenômeno ocorrido com os efeitos tratados pela abordagem do efeito transbordo (spillover). Esta abordagem trata do comportamento do gestor que utiliza dos artifícios espaciais para a manutenção do poder. Assim, infere-se que tais práticas de accounting gimmicks podem ocorrer com maior frequência. Sugere-se ainda a verificação do comportamento das variáveis para o Distrito Federal, já que sua retirada da pesquisa permitiu a identificação de uma subamostra.

\section{REFERÊNCIAS}

Alesina, A. (1987). Macroeconomic Policy in a Two-Party System as a Repeated Game. The Quartely Journal of Economics, 102(3), 651-678. https://doi.org/10.2307/1884222

Alesina, A.; \& Bayoumi, T. (1996). The costs and benefits of fiscal rules: evidence from US states (No. 5614). Cambridge. Recuperado de https://www.nber.org/papers/w5614.pdf 
Almeida, R. B., \& Sakurai, S. N. (2018). Incentivos eleitorais e regras fiscais (não tão) rígidas: novas evidências para os municípios brasileiros a partir da rubrica restos a pagar. In Anais do XLIV Encontro Nacional de Economia (pp. 1-18). Brasil. Recuperado de https://www.anpec.org.br/encontro/2016/submissao/files

Alt, J.E., \& Lassen, D.D. (2006). Fiscal transparency, political parties, and debt in OECD countries. European Economic Review, 50, 1403-1439. https://doi.org/10.1016/j.euroecorev.2005.04.001

Alt, J., Lassen, D.D., \& Wehner, J. (2014). It Isn' † Just about Greece: Domestic Politics, Transparency and Fiscal Gimmickry in Europe. British Journal of Political Science, 44(4), 707-716. https://doi.org/10.1017/S0007123414000064

Alves, A.J.S., Oliveira, R.C R., \& Dantas, C. N. (2017). Desafios da Gestão dos Restos a Pagar na Administração Pública Municipal. In Congresso de Gestão, Negócio e Tecnologia (pp. 1-15). Recuperado de https://eventos.set.edu.br/index.php/congenti/article/view/8146

Aquino, A.C.B., \& Azevedo, R.R. (2017). Restos a pagar e a perda da credibilidade orçamentária. Revista de Administração Pública, 51(4), 580-595. https://doi.org/http://dx.doi.org/10.1590/0034-7612163584

Arestis, P., \& Sawyer, M. (2008). New consensus macroeconomics and inflation targeting Keynesian critique, Economia e Sociedade (1), 629-653. http://dx.doi.org/10.1590/S0104-06182008000400006

Arvate, P.R., Avelino, G., \& Lucinda, C.R. (2008). Existe Influência da Ideologia sobre o Resultado Fiscal dos Governos Estaduais Brasileiros? Est. Econo., 38(4), 789-814. Recuperado de http://www.scielo.br/pdf/ee/v38n4/v38n04a04.pdf

Beck, A. W. (2018). Opportunistic financial reporting around municipal bond issues. Rev Account Stud, 23, 785-826. https://doi.org/10.1007/s 1 1142-018-9454-2

Besley, T.; \& Case, A. (2003). Political Institutions and Policy Choices: Evidence from the United States. Journal of Economic Literature, XLI(March), 7-73. https://doi10.1257/002205103321544693

Bogoni, N., Hein, N., \& Beuren, I. (2011). Análise da relação entre crescimento econômico e gastos públicos nas maiores cidades da região Sul do Brasil. Revista de Administração Pública, 45(1), 159 a 179. https://doi.org/10.1590/S0034-76122011000100008

Brambor, T., \& Ceneviva, R. (2012). Reeleição e Continuísmo nos Municípios Brasileiros. Novos Estudos - CEBRAP, 93, 9-21. https://doi.org/http://dx.doi.org/10.1590/S0101-33002012000200002

Brasil, (2000). Lei Complementar n. ${ }^{\circ} 101$, de 04 de maio de 2000. Estabelece normas de finanças públicas voltadas para a responsabilidade na gestão 
Gastos Sociais e Accounting Gimmicks: Uma Percepção dos Ciclos Políticos Eleitorais nos Municípios do Centro-Oeste Brasileiro

fiscal e dá outras providências. Recuperado de http://www.planalto.gov.br/ccivil 03/LEIS/LCP/LCP101.htm

Buti, M., Martins, J. N, \& Turrini, A. (2007). From Deficits to Debt and Back: Political Incentives under Numerical Fiscal Rules. Economic Studies, 53 (February), 115152. https://doi.org/10.1093/cesifo/ifm003

Clémenceau, M., \& Soguel, N. (2017). Does personal background influence a finance minister to cook the books? An investigation of creative accounting in Swiss cantons. Applied Economics, 49(10), 941-953. https://doi.org/10.1080/00036846.2016.1208360

Coate, S., \& Knight, B. (2011). Government Form and Public Spending: Theory and Evidence from US Municipalities, 3(August), 82-112.

Corrar, L. J., Paulo, E. \& Dias Filho, J. M. (2009). Análise Multivariada para cursos de Administração, Ciências Contábeis e Economia. Ed. Atlas, São Paulo.

Costa, G. P. L., \& Gartner, I. R. (2015). Manipulação de informações contábeis no setor público brasileiro: evidências em dez casos pesquisados. Revista Contemporânea de Contabilidade, 12(26), 141-162. https://doi.org/10.5007/2175-8069.2015v12n26p141

Dalmonech, L. F., Sant'Anna, J. M. B., Coimbra, P. C, \& Teixeira, A. J. C. (2008). Earnings Management e Administração Pública. In XXXIl Encontro da ANPAD. Rio de Janeiro/ RJ. Recuperado de http://www.anpad.org.br/ anpad/eventos.php

Dal-Ri, F.; \& Correia, F. M. (2019). Ciclos político-eleitorais e alocação dos gastos públicos: uma análise para os municípios brasileiros. Revista De Economia, 40(73), 305-322. http://dx.doi.org/10.5380/re.v40i73.68176

Downs, A. (1957). An economic theory of political action in a democracy. Journal of political economy, 65(2), 135-150. https://doi.org/10.1086/257897

Drazen, A., \& Eslava, M. (2005). Lectoral Manipulation via Expenditure Composition: Theory and Evidence (No. 11085). Cambridge. Recuperado de https://www.nber.org/papers/w1 1085.pdf

Duggan, J., \& Martinelli, C. (2015). The Political Economy of Dynamic Elections: A Survey and Some New Results. Fairfax. Recuperado de http://edirc.repec.org/data/icgmuus.html

Fatás, A.; Mihov, I. (2006). The macroeconomic effects of fiscal rules in the US states. Journal of Public Economics, 90, 101-117. https://doi.org/10.1016/i.jpubeco.2005.02.005

Fávero, L.P; \& Belfiore, P. (2017). Análise de dados: modelos de regressão com Exce/ß, Stata® e SPSS ${ }^{\circledR}$. Elsevier Brasil. 
Field, A. (2009). Descobrindo a estatística usando o SPSS. Trad. Lorí Vialli. 2 ed. Porto Alegre: Artmed.

Fiirst, C., Baldissera, J. F., Martins, E. B., \& Nascimento, S. A. A. (2018). A Influência dos Índices Socioeconômicos e Contábeis no nível de Transparência Eletrônica dos Estados Brasileiros sob a ótica da Teoria da Escolha Pública. Administração Pública e Gestão Social, 10(4), 272-281. https://doi.org/0.21118/apgs.v10i4.2008

Freire, F. S; Monteiro, A.J; Vieira, L.M; Santos, M.m.; \& Freire Filho, R (2007). Finanças públicas municipais: indicadores de desempenho fiscal do nordeste brasileiro. Banco do Nordeste. UFC Edições

Gámez, C., \& Ibarra-yúnez, A. (2009). El ciclo político oportunista y el gasto de los estados mexicanos. Gestión y Política Pública, XVIII (81), 39-65. Recuperado de http://www.scielo.org.mx/scielo.php?script=sci arttext\&pid=s 1405

Gobetti, S. W. (2010). Ajuste Fiscal nos Estados: uma análise do período 1998-2006. Revista de Economia Contemporânea, 14(1), 113-140. Retrieved from https://revistas.ufrj.br/index.php/rec/article/view/30303

Gobetti, S. W. (2014). Regras fiscais no Brasil e na Europa: Um estudo comparativo e propositivo, Texto para Discussão, No. 2018, Instituto de Pesquisa Econômica Aplicada (IPEA), Brasília. Recuperado de https://www.econstor.eu/handle/10419/121671

Gobetti, S W; Orair, O. (2017). Resultado primário e contabilidade criativa: Reconstruindo as estatísticas fiscais "acima da linha" do governo geral (No. 2288). Brasília. Recuperado de http://hdl.handle.net/10419/177504

Gonçalves, R. C. (2018). Regime de Metas Fiscais no Brasil Frente aos Ciclos Econômicos: uma crítica pós-keynesiana. In Encontro Nacional de Economia Política (pp. 1-25). Niterói - RJ. Recuperado de http://www.sep.org.br/anais/Trabalhos para o site/Area 3/51.pdf

Goto, T., \& Yamamoto, G. (2018). Creative Accounting and Municipal Mergers -A Theoretical and Empirical Approach. Osaka. Recuperado de http://www.osipp.osaka-u.ac.jp/archives/DP/2018/DP2018E012.pdf

Gujarati, D. N.; \& Porter, D. C. (2011). Basic Econometrics. 5. ed. New York: McGraw Hill.

Hair, J. F., Black, R, Babin, E. Anderson, R,.\& Tatham, L (2009). Análise multivariada de dados. Bookman Editora Porto Alegre

Hodges, R. (2018). How might harmonization influence the future prevalence of public sector creative accounting? (2018), 3-14. https://doi.org/10.2478/tekhne-2019-0001 
Gastos Sociais e Accounting Gimmicks: Uma Percepção dos Ciclos Políticos Eleitorais nos Municípios do Centro-Oeste Brasileiro

Koen V., \& Van den Noord. P. (2005). Fiscal Gimmickry in Europe (No. 417). Paris. Recuperado de https://www.oecd-ilibrary.org/content/paper/237714513517

Lledó, V; Yoon, S; Fang, X; Mbaye, S; Kim, Y. (2017). Fiscal Rules at a Glance. International Monetary Fund. Recuperado de http://www.imf.org/external/datamapper/fiscalrules/Fiscal Rules at a Glance - Background Paper.pdf

Macedo, J. de J., \& Corbari, E. C. (2009). Efeitos da Lei de Responsabilidade Fiscal no endividamento dos Municípios Brasileiros: uma análise de dados em painéis. Revista Contabilidade \& Finanças, 20(51), 44-60. Recuperado em: https://www.redalyc.org/pdf/2571/257119520003.pdf

Menezes, R. T; Toneto Júnior, R. (2006). Regras fiscais no Brasil: a influência da LRF sobre as categorias de despesa dos municípios. Planejamento e Políticas Públicas (PPP), 29(jun/dez), 7-37. Recuperado de http://ipea.gov.br/ppp/index.php/PPP/article/view/41/40

Milesi-ferretti, G M; Perotti, R; \& Rostagno, M. (2002). Electoral systems and public spending. The Quarterly Journal of Economics, 117(May), 609-657. https://doi.org/https://doi.org/10.1162/003355302753650346

Milesi-ferretti, G. M. (2003). Good, bad or ugly? On the effects of fiscal rules with creative accounting. Journal of Public Economics, 88, 377-394. https://doi.org/10.1016/S0047-2727(02)00076-2

Montes, G. C., \& Alves, C. (2012). O debate acerca dos objetivos e condução da política fiscal:uma abordagem crítica a visão convencional. Economia e Sociedade, 2(2), 363-386. http://dx.doi.org/10.1590/S010406182012000200006 .

Nakaguma, M. Y., \& Bender, S. (2006). A emenda da reeleição e a Lei de Responsabilidade Fiscal: impactos sobre ciclos políticos e performance fiscal dos Estados (1986-2002). Economia Aplicada, 10(3), 377-397. Recuperado de http://www.scielo.br/pdf/ecoa/v10n3/a05v10n3.pdf

Nakaguma, M. Y., \& Bender, S. (2010). Ciclos Políticos e Resultados Eleitorais: Um Estudo sobre o Comportamento do Eleitor Brasileiro. Revista Brasileira de Economia, 64(1), 3-24. https://doi.org/http://dx.doi.org/10.1590/S0034$\underline{71402010000100001}$

Neduziak, L. C. R., \& Correia, F. M. (2018). Orçamento estadual e o ciclo político orçamentário: uma análise para os gastos por categoria econômica utilizando um painel dinâmico. Revista Econômica do Nordeste, 49(2), 63-78. Recuperado de https://ren.emnuvens.com.br/ren/article/view/640/713

Nordhaus, W.D. (1975), "The Political Business Cycle", Review of Economic Studies, Vol. 42, No. 2, pp. 169-90 
Oliveira, F. A. de. (2011). Contabilidade Criativa: como chegar ao paraíso, cometendo pecados contábeis - o caso do governo do Estado de Minas Gerais. Revista de História Econômica \& Economia Regional Aplicada, 6(11), 1-20. Recuperado de http://www.ufjf.br/heera/files/2009/11/1ContabilidadeCriativa-1-para-pdf.pdf

Orair, R. O. (2016). Política fiscal no Brasil contemporâneo: investimento público e ciclos econômicos. In A. K. P. Alexandre de Ávila Gomide (Ed.), Governança da política de infraestrutura: condicionantes institucionais ao investimento (IPEA, pp. 165-185). Rio de Janeiro/ RJ.

Orair, R. O., \& Siqueira, F. de F. (2016). Investimento Público no Brasil: trajetória recente e relações com ciclo econômico e regime fiscal. Economia e Sociedade, 3(64), 939-969. https://doi.org/http://dx.doi.org/10.1590/19823533.2018v27n3art9

Orair, R. O., \& Siqueira, F. D. F. (2018). Investimento público no Brasil e suas relações com ciclo econômico e regime fiscal. Economia e Sociedade, 27(3), 939969. https://doi.org/10.1590/1982-3533.2018v27n3art9

Ozkaya, A. (2014). Creative Accounting Practices and Measurement Methods: Evidence from Turkey. Economics, 8(2015), 0-28. https://doi.org/http://dx.doi.org/10.5018/economics-ejournal.ja.2014-29

Reischmann, M. (2015). Creative accounting and electoral motives: Evidence from OECD countries. Journal of Comparative Economics, 44(2), 243-257. https://doi.org/10.1016/j.jce.2015.07.001

Rezende, C. (2008). Teoria comparada e a economia política da expansão dos gastos públicos. Economia Aplicada, 12(4), 607-633. https://doi.org/http://dx.doi.org/10.1590/S1413-80502008000400004

Rezende, F.C. (1997). Descentralização, Gastos Públicos e Preferências Alocativas dos Governos Locais no Brasil: (1980-1994). Dados, 40(3). https://dx.doi.org/10.1590/S0011-52581997000300005

Ribeiro, C.P. de P., \& Zuccolotto, R. (2014). A face oculta do Leviatã: transparência fiscal nos municípios brasileiros e suas determinantes socioeconômicas e fiscais. Enfoque: Reflexão Contábil, 33(1), 37-52. https://doi.org/10.4025/enfoque.v33i1.19619

Rogoff, K. \& Sibert, A. (1986). "Elections and Macroeconomic Policy Cycles". NBER Working Paper n. 1838.

Rose, S. (2006). Do fiscal rules dampen the political business cycle? Public Choice, 128, 407-431. https://doi.org/10.1007/s $11127-005-9007-7$

Sacchi, A., \& Salotti, S. (2015). The impact of national fiscal rules on the stabilisation function of fiscal policy. European Journal of Political Economy, 37, 1-20. https://doi.org/10.1016/i.ejpoleco.2014.10.003 
Gastos Sociais e Accounting Gimmicks: Uma Percepção dos Ciclos Políticos Eleitorais nos Municípios do Centro-Oeste Brasileiro

Sakurai, S. N. (2009). Ciclos Políticos nas Funções Orçamentárias dos Municípios Brasileiros: Uma Análise para o Período. Estud. Econ., 39(1), 39-58. https://doi.org/http://dx.doi.org/10.1590/S0101-41612009000100002

Salvador, E. (2016). Fundo Público e o financiamento das Políticas Sociais no Brasil 1 Public fund and the financing of social policies in Brazil. Serv. Soc. Rev, 14(2), 04-22. https://doi.org/10.5433/1679-4842.2012v14n2p4

Santos, P. S. A.; Machado, D. G., \& Scarpin, J. E. (2013). Gerenciamento de Resultados no Setor Público: Análise por meio das Contas Orçamentárias Outras Receitas e Despesas Correntes dos Municípios de Santa Catarina. Contabilidade Vista \& Revista, 23(4), 15-43. https://revistas.face.ufmg.br/index.php/contabilidadevistaerevista/article/vie w/2001.

Silva, A. de A. P. S., Ferreira, M. A. M., Braga, M. J., \& Abrantes, L. A. (2012). Eficiência na Alocação de Recursos Públicos Destinados à Educação, Saúde e Habitação em Municípios Mineiros. Contabilidade Gestão e Governança, 15(1), 96-114. Recuperado em https://www.revistacgg.org/contabil/article/view/389

Silva, E. B. (2018). Práticas de contabilidade criativa nos estados brasileiros: influências dos ciclos eleitorais. (Dissertação de Mestrado). Universidade de Brasília - UnB, Brasília, Brasil. Recuperado em https://repositorio.unb.br/handle/10482/32534

Simonassi, A. G.; Cândido Junior, J. O. (2008). Desempenho Fiscal e os Impactos sobre as responsabilidades fiscal e social nos Estados e regiões brasileiras. Texto para Discussão, No. 1323, Instituto de Pesquisa Econômica Aplicada (IPEA), Brasília. Recuperado em http://repositorio.ipea.gov.br/handle/1 1058/1469

Soares, R. F., Clemente, A., Freire, F. de S., \& Scarpin, J. E. (2016). Centralidade municipal e interação estratégica na decisão de gastos públicos em saúde. Revista de Administração Pública, 50(4), 563-585. http://dx.doi.org/10.1590/0034-7612145797

Souza, S. (2013). Austeridade fiscal versus contabilidade criativa: uma nova práxis para o velho ímpeto oportunista. Leviathan | Cadernos de Pesquisa Política, 6, 127-152. https://doi.org/10.11606/issn.2237-4485.lev.2013.132326

Souza, S. S. D. E. (2008). A fria austeridade das regras fiscais resiste ao calor das urnas? Oportunismo fiscal e contabilidade criativa nos estados brasileiros. (Tese de Doutorado). Universidade Federal de Pernambuco - UFPE, Pernambuco, Brasil. Recuperado em https://attena.ufpe.br/handle/123456789/1357 
Stolowy, H., \& Breton, G. (2004). Accounts manipulation: A literature review and proposed conceptual framework. Review of accounting and finance, 3(1), 592. https://doi.org/10.1108/eb043395

Videira, R. A.; \& Mattos, E. (2011). Ciclos políticos eleitorais e a interação espacial de políticas fiscais entre os municípios brasileiros. Economia Aplicada, 15(2), 259-286. https://doi.org/http://dx.doi.org/10.1590/S1413-80502011000200005

Vinnari, E. M.; \& Näsi, S. (2008). Creative Accrual Accounting in the Public Sector: "milking" water utilities to balance municipal budgets abd accounts. Financial Accountability \& Management, 24(May), 97-116. https://doi.org/https://doi.org/10.1111/j.1468-0408.2008.00448.x

Von Hagen, J., \& Wolff, G. B. (2006). What do deficits tell us about debt? Empirical evidence on creative accounting with fiscal rules in the EU. Journal of Banking \& Finance, 30(12), https://doi.org/10.1016/j.jbankfin.2006.05.011

Weber, A. (2012). Stock-Flow Adjustments and Fiscal Transparency: A CrossCountry Comparison. IMF Working Papers (Vol. 12). https://doi.org/10.5089/9781463933821.001

Werck, K.; Heyndels, B; \& Geys, B. (2008). The impact of 'central places' on spatial spending patterns: evidence from Flemish local government cultural expenditures. Journal of Cultural Economics, 32, 35-58. https://doi.org/10.1007/s10824-007-9056-5

\section{CONTRIBUIÇÕES DOS AUTORES}

\begin{tabular}{|l|c|c|}
\hline \multicolumn{1}{|c|}{ Contribuição } & $\begin{array}{c}\text { Nilton Oliveira da } \\
\text { Silva }\end{array}$ & $\begin{array}{c}\text { Fátima de Souza } \\
\text { Freire }\end{array}$ \\
\hline $\begin{array}{l}\text { 1. Idealização e concepção do assunto e } \\
\text { tema da pesquisa }\end{array}$ & $\checkmark$ & $\checkmark$ \\
\hline 2. Definição do problema de pesquisa & $\checkmark$ & $\checkmark$ \\
\hline 3. Desenvolvimento da Plataforma Teórica & $\checkmark$ & $\checkmark$ \\
\hline $\begin{array}{l}\text { 4. Delineamento da abordagem } \\
\text { metodológica da pesquisa }\end{array}$ & $\checkmark$ & $\checkmark$ \\
\hline 5. Coleta de dados & $\checkmark$ & $\checkmark$ \\
\hline $\begin{array}{l}\text { 6. Análises e interpretações dos dados } \\
\text { coletados }\end{array}$ & $\checkmark$ & $\checkmark$ \\
\hline 7. Conclusões da pesquisa & $\checkmark$ & $\checkmark$ \\
\hline 8. Revisão crítica do manuscrito & $\checkmark$ & $\checkmark$ \\
\hline $\begin{array}{l}\text { 9. Redação final do manuscrito, conforme as } \\
\text { normas estabelecidas pela Revista. }\end{array}$ & $\checkmark$ & \\
\hline 10. Orientação & & \\
\hline
\end{tabular}

